\title{
Do For-Profit Health Plans Restrict Access to Care Under Medicaid Managed Care?
}

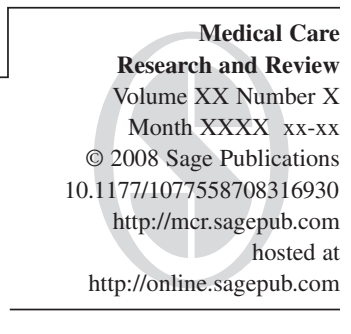

\author{
Sharon K. Long \\ The Urban Institute
}

\begin{abstract}
Managed care is now the norm for many on Medicaid, with approximately 19 million people on Medicaid enrolled in health maintenance organizations. In 2005, nearly 300 plans nationwide participated in state Medicaid managed care programs, with many of those plans operating under for-profit ownership. Concerns about the impact of plan ownership on access to care arise because of differences in the incentives in place in forprofit and nonprofit organizations that may lead for-profit plans to restrict access to care. Using data from the 2002 National Survey of America's Families on plan enrollment for a national sample of Medicaid enrollees, this study examines the link between for-profit plan ownership and enrollees' access to health care. The results suggest that access to care for Medicaid enrollees may be better under nonprofit plans than for-profit plans.
\end{abstract}

Keywords: Medicaid; managed care; HMOs; for-profit

$\mathrm{M}$

anaged care is now the norm for many on Medicaid, with nearly two thirds of the 45 million people on Medicaid enrolled (Centers for Medicare and Medicaid Services, 2005). Increasingly, states are relying on fully capitated comprehensive health plans to manage care for Medicaid enrollees. ${ }^{1}$ In 2005, approximately 19 million Medicaid enrollees were in health maintenance organizations (HMOs), up from about 12 million in 2000. Serving those enrollees, nearly 300 plans nationwide participated in state Medicaid managed care programs in 2005, with many of those plans operating under for-profit ownership.

Concerns about the impact of plan ownership on access to care arise because of the differences in the incentives in place in for-profit and nonprofit organizations that may lead to differences in plan behaviors. For-profit health plans may have an incentive to restrict access to care in an effort to insure profits for shareholders, whereas nonprofit plans may be motivated by other goals (e.g., maximization of output, charity care, or quality of care). Furthermore, administrators at nonprofit plans, because they are prohibited from sharing in surplus revenues (profits), may have less incentive than those at for-profit plans to pursue activities solely to generate profits

Author's Note: Please address correspondence to Sharon K. Long, The Urban Institute, 2100 M Street NW, Washington, DC 20037; phone: 202-261-5656; e-mail: Slong@ui.urban.org. 
(Schlesinger, Mitchell, \& Gray, 2003). In addition, nonprofit plans, because they tend to have more open governance arrangements and local community representation on their boards, may be more constrained in their ability to restrict access to care than are for-profit plans (Schlesinger, Quon, Wynia, Cummins, \& Gray, 2005).

\section{New Contribution}

Prior work on the link between plan for-profit status and access to care under Medicaid has been limited by a lack of data for a nationally representative sample of Medicaid enrollees. Because of this limitation, work to date has tended to focus on Medicaid plans in a single state, especially around issues of mental health care (Bloom et al., 2002; Hill, Thornton, Trenholm, \& Wooldridge, 2002; Shenkman, Wu, Nackashi, \& Sherman, 2003). This study takes advantage of new data in the 2002 National Survey of America's Families (NSAF) that, for the first time in a national survey, included a question on managed care plan name for Medicaid enrollees. By matching managed care plan name with data on the plan's ownership, this study is able to examine the association between a plan's for-profit status and access to health care for a national sample of enrollees in Medicaid.

\section{Conceptual Model}

The study relies on a traditional conceptual model to examine health care access (Andersen, 1995; Andersen \& Newman, 1973). Under this framework, access to health care is modeled as a function of the predisposition of the individual to use services, factors that enable or impede use, and the individual's need for services. The for-profit ownership status of the enrollee's Medicaid plan enters the model as a factor that has the potential to enable or impede access to care. The access measures considered in the article are the following: whether the Medicaid enrollee had a visit to a doctor or other health professional in the last year, unmet need for health care, and unmet need for prescription drugs. If, as some would suggest, for-profit plans are more likely to restrict access to care than nonprofit plans, enrollees in for-profit plans would be expected to be less likely to report a health care visit and to be more likely to report unmet need for care, all else equal.

\section{Method}

State Medicaid programs typically establish contracts with multiple managed care plans. Program enrollees are encouraged to consider the costs and benefits associated with the different managed care plans and to select the plan that best meets their needs. Although many Medicaid enrollees do choose a particular plan from among 
the set of plans that are available to them, some individuals fail to select a plan and are, subsequently, assigned to a plan by the state. Given this plan selection/assignment process, comparing access to care across different types of managed care plans is complicated because any observed differences could be due to the managed care plan or to factors that affect the individual's enrollment in a particular type of plan. A variety of factors may underlie an individual's plan choice or, for those who do not choose, the state's process of plan assignment under Medicaid. If these factors also directly affect the individual's health care access, then observed differences in access between enrollees in for-profit and nonprofit plans may be because of, in part, unmeasured differences between the individuals rather than their enrollment status, biasing the estimates of the impacts of profit status.

To account for the possibility that there may be unobserved factors that both affect an individual's enrollment in a for-profit health plan and his or her health care access, the following model is estimated.

$$
A_{i}=X_{i} \beta_{1}+P_{i} \gamma+\varepsilon_{i},
$$

where $A$ is a measure of access to care, $X$ is a vector of exogenous control variables, and $\varepsilon$ is the error term. $P$ is an indicator of the individual's enrollment in a for-profit plan and $\gamma$ provides the estimate of the impact of the individuals enrollment in a forprofit plan on access to care. The possibility of biased estimates arises when $P$ is simultaneously determined with $A$. One strategy to correct for this possibility is to identify one or more variables, $Z$, that are correlated with $P$ but do not enter the access equation (i.e., are uncorrelated with $Z$ ):

$$
P_{i}=X_{i} \beta_{2}+Z_{i} \delta+\eta_{\mathrm{i}}
$$

In this article, Equations 1 and 2 are estimated using instrumental variables (IV) methods to obtain a consistent estimate of $\gamma$ (McClellan \& Newhouse, 2000). The central challenge in estimating this IV model is to identify the instruments $(Z)$ that are highly correlated with the individual's enrollment in a for-profit plan but not correlated with his or her access to care. In this article, the profit status of the set of plans available under Medicaid in the enrollee's county of residence is used as the instrument for enrollment in a for-profit plan. Specifically, two variables are included in the model: (a) the total number of for-profit plans and (b) the total number of nonprofit plans available to the Medicaid enrollee in his or her county of residence.

Whether the instruments fully correct for selection bias in the access equations (Equation 1) depend on the instruments' explanatory power in Equation 2 and on whether the instruments can appropriately be excluded from Equation 1 (Wooldridge, 2002). As will be shown, the set of instruments has good predictive power in Equation 2, indicating that the instruments are strongly correlated with enrollment in a for-profit plan. Furthermore, the instruments are found to have no 
independent effects on the measures of access in Equation 1. Together, these suggest that the influence of the instruments is only through their effect on plan profit status and not through any direct effect on health care access.

Given that the outcome variables ( $A$ and $P$ in Equations 1 and 2 ) are binary variables, the analysis relies on probit regression models that are estimated using the probit and ivprobit commands in Stata using maximum likelihood estimation (StataCorp, 2007). However, the models are also estimated using a linear probability framework to take advantage of the tests of the assumptions underlying the IV model that are available in the ivreg2 command in Stata.

\section{Data}

The study relies on data from the 2002 NSAF that collected economic, health, and social characteristics for a representative sample of families. ${ }^{2}$ Of particular relevance given the focus in this study on the Medicaid program, the survey oversamples families with incomes less than $200 \%$ of the federal poverty line. The survey also included oversamples in 13 study states. The overall survey response rate for adults, the population that is the focus of this study, was $52 \%$ in 2002 . Responses to the interviews were weighted to adjust for the oversampling of low-income families, nonresponse, and undercoverage (Brick, Ferraro, \& Strickler, 2004).

All of the findings reported here are based on weighted analyses that account for the complex design of the survey. The analyses were conducted with Stata 10.0, using the survey commands (svy) for the probit and ivprobit models (StataCorp, 2007). For the ivreg 2 models, where the svy commands are not available, the Huber/White sandwich estimator of variance is used with an adjustment for clustering within the NSAF survey strata.

As noted above, the 2002 NSAF included a new question that asked Medicaid enrollees who reported that they were enrolled in managed care to name their health plan. Individuals were identified as being enrolled in Medicaid managed care if they answered yes to the following question:

- Under Medicaid, are you signed up with an HMO, that is, a health maintenance organization? With an HMO, you must generally receive care from HMO doctors; otherwise, the expense is not covered unless you were referred by the HMO or there was a medical emergency.

Respondents who reported they were enrolled in managed care were then asked the following question:

- Medicaid provides care through several different (HMOs/companies or plans). What is the name of the (HMO/company or plan) you are signed up with under Medicaid? It would be the name on your insurance card, not the name of your doctor. 
To facilitate the correct reporting of plan names in the survey, the names of the six largest plans serving the Medicaid population in the state were included in the response categories available to the respondents in each state. Although the list of plans was not read to the respondents, interviewers could read back plan names to respondents to confirm their reported plan name, improving the accuracy of the coding of Medicaid plan name.

Among Medicaid enrollees in the sample who reported that they were in a managed care, $84 \%$ reported a plan name that could be linked to one of the Medicaid managed care plans available in their county of residence. (The focus here is on managed care plans providing comprehensive medical care. Plans that cover a limited set of services, such as mental health or dental care, are not included in this analysis.) The remaining enrollees who reported that they were in managed care either did not know the name of their plan or reported a name that could not be matched to any of the medical plans that were available under Medicaid in their county. In some cases, individuals who reported that they were enrolled in a managed care plans reported the name of the state's primary care case management program. Others who reported being in managed care but could not name a health plan may also be enrolled in a primary care case management program as many named a physician or clinic as their "plan." Unfortunately, it is not possible to link the NSAF data to administrative sources to check the quality of reported data on Medicaid plan name. With no way of assigning a plan name based on the reported information for these respondents, individuals who did not report a valid Medicaid health plan are excluded from the analysis. ${ }^{3}$

The reported plan name is used to link information on the plan's profit status to the NSAF data. Information on plan profit status is obtained from InterStudy, state managed care associations and, in a few cases, individual health plan Web sites. ${ }^{4}$ Beyond NSAF and the plan data, data from the Area Resource File is used to capture the characteristics of the health care market in the individual's county of residence. These characteristics include the supply of physicians and hospital beds in the county. County (or county equivalent) is used as a measure of the local health care market because it is the smallest geographic unit for which local health care market data were available for the entire nation. The county measures serve as proxies for the health environment in the individual's local community.

Medicaid covers three broad eligibility groups for nonelderly adults: pregnant women, adults in families with dependent children, and adults with severe disabilities. This study focuses on pregnant women and adults in families with dependent children who were enrolled in Medicaid for the full year. Disabled adults are excluded from the analysis as they often face a different set of plan choices than that of the general adult Medicaid population (which was not captured in our plan data). ${ }^{5}$ Finally, the analysis is limited to urban areas as fully capitated managed care is largely concentrated in urban areas under the Medicaid program. The final sample size for the study is 495 adults. 
Table 1

Explanatory Variables in the Models

\begin{tabular}{lr}
\hline Characteristic & Mean or Percentage \\
\hline Plan choice & \\
$\quad$ Enrolled in a for-profit plan (\%) & 57.5 \\
Instruments for plan choice & \\
Number of for-profit plans available in county of residence (mean) & 2.8 \\
Number of nonprofit plans available in county of residence (mean) & 2.2 \\
Individual and community characteristics & \\
Age (years) & 33.1 \\
Age squared (years) & 1165.2 \\
Female (\%) & 77.5 \\
Black, non-Hispanic (\%) & 30.2 \\
Hispanic (\%) & 24.9 \\
Never married (\%) & 48.4 \\
High school graduate (\%) & 59.8 \\
In fair or poor health (\%) & 27.0 \\
Has work limitation (\%) & 23.5 \\
Pregnant in last year (\%) & 11.1 \\
Number of MDs per 1000 population in county of residence (mean) & 3.1 \\
Number of hospital beds per 1000 population in county of residence (mean) & 3.2 \\
\hline
\end{tabular}

Source: National Survey of America's Families $2002(N=495)$.

Because of the relatively small sample size for the study, parsimonious models of health care access are estimated. The empirical model is based on the conceptual model outlined above. Predisposing factors in the model include age, gender, and race/ethnicity. Enabling or impeding factors include the individual's marital status and education as proxies for economic well-being, along with the profit status of their health plan and the characteristics of their local health care market. Finally, health care need is measured by the individual's health status, disability status, and whether they were pregnant in the last year. Table 1 summarizes the explanatory variables included in the model, including the share of the sample enrollment in a for-profit Medicaid plan (58\%).

As noted above, the IV model relies on the number of for-profit and nonprofit Medicaid plans available to the Medicaid enrollee as the instruments for enrollment in a for-profit plan. On average, there were 2.8 for-profit Medicaid plans and 2.2 nonprofit Medicaid plans available to the Medicaid enrollees in their county of residence. In general, the share of individual's enrolled in a for-profit plan increased as the number of for-profit plans in a county increased. For those who enrolled in a forprofit plan, there were, on average, 3.6 for-profit plans and 1.6 nonprofit plans available. The comparable figures for those who enrolled in a nonprofit plan were 1.7 for-profit and 3.0 nonprofit plans, respectively. 
Table 2

Summary of Access and Use Measures

\begin{tabular}{lc}
\hline & Percentage \\
\hline Doctor visit in last year & 81.3 \\
Other health professional visit in last year & 28.0 \\
Unmet need for medical care in last year & 10.9 \\
Unmet need for prescription drugs in last year & 9.0 \\
\hline
\end{tabular}

Source: National Survey of America's Families $2002(N=495)$.

\section{Results}

As shown in Table 2, $81 \%$ of the sample members reported a doctor visit and $28 \%$ reporting a visit to another health professional in the past year. Even so, there is some evidence of problems with access to care, as unmet need for medical care or surgery and unmet need for prescription drugs were reported by $11 \%$ and $9 \%$ of the sample, respectively. To place these figures in context, among adults with private coverage in 2002, the share reporting health care visits was similar: $76 \%$ reported a doctor visit and $32 \%$ reported a visit to another health professional. However, unmet need for care was lower among adults with private coverage than for the Medicaid managed care sample: $5.5 \%$ reported unmet need for medical care or surgery and 5\% reported unmet need for prescription drugs.

Table 3 reports the estimates of the marginal effect of enrollment in a for-profit Medicaid plan on access to care based on a simple probit model (ignoring the potential endogeneity of plan enrollment) and the IV probit models. Before reviewing those results, it is important to assess the IV model, particularly the explanatory power of the instruments in Equation 2 and whether the instruments can appropriately be excluded from Equation 1. Table 4 presents the estimates for the model of enrollment in a for-profit plan (Equation 1) based on a simple probit model. (In estimating the Equations 1 and 2 using the ivprobit command, the two equations are actually estimated jointly; unfortunately, it is not possible to obtain the output from that estimation of Equation 1 from Stata when using the svy command.)

As shown in Table 4, the two instruments are each significant predictors of enrollment in a for-profit plan $(p<.001)$. As noted above, a linear probability version of the model is also estimated to take advantage of the additional tests available in the ivreg2 command in Stata. That analysis finds a Shea partial $R^{2}$ of .346 for the equation, indicating that the instruments are strongly correlated with for-profit plan choice. There is also evidence that the instruments have no independent effects on access as indicated by the Hansen's J test that was not statistically significant for any of the models (column 3 in Table 3). The Hansen's J test is a test of the joint null hypothesis that the instruments are valid instruments (i.e., uncorrelated with the 
Table 3

\section{Estimates of the Marginal Effect of Being Enrolled in a For-Profit Plan Based on Simple Probit and IV Probit Models}

\begin{tabular}{lccc}
\hline & & IV Probit \\
\cline { 3 - 4 } & & $\begin{array}{c}\text { Test of } \\
\text { Overidentifying } \\
\text { Restrictions } \\
(\text { Hansen's J })^{\mathrm{a}}\end{array}$ \\
\hline $\begin{array}{l}\text { Any doctor visit in the last } 12 \text { months } \\
\text { Any other health professional visit in } \\
\text { the last } 12 \text { months }\end{array}$ & $-0.016(0.036)$ & $-0.137 * *(0.068)$ & $0.016(p=0.900)$ \\
$\begin{array}{l}\text { Any unmet need for medical care in } \\
\text { the last } 12 \text { months }\end{array}$ & $-0.053(0.056)$ & $-0.035(0.057)$ & $0.589(p=0.443)$ \\
$\begin{array}{l}\text { Any unmet need for prescription drugs in } \\
\text { the last } 12 \text { months }\end{array}$ & $0.007(0.027)$ & $0.059(0.041)$ & $0.635(p=0.425)$ \\
\hline
\end{tabular}

Source: National Survey of America's Families $2002(N=495)$.

Note: Standard errors in parentheses. Estimation results are based on a regression model controlling for the individual's age, sex, race/ethnicity, marital status, education, health status, disability status, pregnancy status, and their local health care market (as measured by the number of the supply of physicians and hospital beds in the individual's county of residence).

a. The null hypothesis is that the instruments are valid instruments.

$* p<.10 . * * p<.05 . * * * p<.01$.

error term) and that they are correctly excluded from the access equations. Finally, tests of weak identification, which arises when the instruments are only weakly correlated with the endogenous regressor, and underidentification are easily rejected. ${ }^{6}$ Taken together, these tests suggest that the influence of the instruments is through their effect on enrollment in a for-profit plan and not through any direct effect on health care access or use, and the effect of the instruments on health plan enrollment is relatively strong. Consequently, in presenting the results in Table 3, the focus is on the findings from the IV probit model.

As shown in Table 3, the findings from the IV model suggest that enrollment in a for-profit Medicaid plan is associated with a lower probability of health care use and greater probability of unmet relative to a nonprofit plan. Specifically, Medicaid enrollees in for-profit plans were significantly less likely to have a visit to a doctor or other health professional in the last 12 months, although only the finding for visits to a doctor is statistically significant (14 percentage points lower than in nonprofit plans). On both of the measures of unmet need for care considered in the studyunmet need for medical care or surgery and unmet need for prescription drugsenrollees in for-profit plans reported higher levels of unmet need (approximately 6 percentage points higher than in nonprofit plans), however, only the finding for unmet need for medical care is statistically significant. 
Table 4

Coefficient Estimates From the Simple Probit Model of Enrollment in a For-Profit Plan

\begin{tabular}{lcc}
\hline & $\begin{array}{c}\text { Coefficient } \\
\text { Estimate }\end{array}$ & $\begin{array}{c}\text { Standard } \\
\text { Error }\end{array}$ \\
\hline Age & $0.128^{*}$ & 0.072 \\
Age squared & -0.002 & 0.001 \\
Female & -0.356 & 0.315 \\
Black, non-Hispanic & -0.078 & 0.361 \\
Hispanic & -0.068 & 0.291 \\
Never married & 0.046 & 0.220 \\
High school graduate & 0.279 & 0.200 \\
In fair or poor health & $-0.475^{*}$ & 0.250 \\
Has work limitation & -0.342 & 0.278 \\
Pregnant in last year & $-0.631^{*}$ & 0.301 \\
Number of MDs per 1000 population in county of residence & 0.002 & 0.072 \\
Number of hospital beds per 1000 population in county of residence & 0.006 & 0.063 \\
Number of for-profit plans available in county of residence & $0.722^{* * *}$ & 0.164 \\
Number of nonprofit plans available in county of residence & $-0.317^{* * *}$ & 0.074 \\
Constant & $-2.858^{*}$ & 1.436 \\
\hline
\end{tabular}

Source: National Survey of America's Families $2002(N=495)$.

$* p=.10 . * * p=.05 . * * * p=.01$.

In contrast to the estimates from the IV model, the estimates from simple probit models (which ignore the potential endogeneity of plan enrollment) are smaller in magnitude and never statistically significant. This suggests that failing to account for unobserved factors would understate the effects of enrollment in a for-profit plan on access to care.

\section{Discussion}

The results of this study suggest that access to care is lower in for-profit than nonprofit plans for Medicaid enrollees. Specifically, Medicaid enrollees in for-profit plans were less likely than those in nonprofit plans to report a health care visit to a doctor and more likely to report unmet need for medical care. Although these findings raise concerns about an increasing reliance on for-profit plans in the Medicaid program, there are several limitations of the study that suggest these findings should be viewed as preliminary. First, like all survey-based research, the analysis is based on self-reported data, raising concerns about both validity and reliability. In particular, the study relies on the individual's self-reported enrollment in a managed care plan and ability to provide the name of their health plan to define the sample. Because there is evidence that individuals misreport managed care enrollment, the sample may not be representative of all Medicaid managed care enrollees nor all enrollees in for-profit plans (Flores, Abreu, 
Sun, \& Tomany, 2004; Reschovsky \& Hargraves, 2000). Second, although IV estimation addresses the potential endogeneity of the plan enrollment process in estimating the effect of enrollment in a for-profit plan on access to care, the model that is estimated may not capture all relevant unobserved factors. As such, the estimates may still be biased (although less so than estimates from models that do not control for the possibility of such endogeneity). To fully remove the possibility of such bias would require random assignment to plans, an approach that is not feasible. Third, the study focuses on a single element of plan type-ownership. However, for-profit and nonprofit plans differ on other attributes as well, with for-profit plans, for example, more likely to be affiliated with a national managed care organization and less likely to serve a predominantly Medicaid population. The sample sizes in this study will not support an analysis that disentangles the effects of different elements of plan types. Finally, the study relies on a cross-sectional analysis that cannot establish causality between plan ownership and access to care, even when strong associations exist. Longitudinal studies are needed to assess causality.

Given these limitations, additional research with better data is needed to fully explore the role of for-profit ownership on health care access under the Medicaid program. The findings from this study should be viewed as providing information to encourage future research. If further research confirms these findings and establishes a link between plan for-profit status and reduced access to care for Medicaid enrollees, policy makers and program administrators would have an evidence base to support stronger performance standards in monitoring Medicaid health plans and establishing policies that promote a larger role for nonprofit ownership of Medicaid plans. Understanding better the role of plan characteristics in care delivery systems is critical for improving the performance of the health care system for Medicaid enrollees.

\section{Notes}

1. The remaining managed care is largely prepaid inpatient care programs, prepaid ambulatory care programs, and primary care case management programs.

2. See www.urban.org/center/anf/nsaf.cfm for more information on the National Survey of America's Families.

3. As a test of the sensitivity of the findings to this sample exclusion, two additional models were estimated that kept those who were unable to provide a valid plan name in the analysis sample, assuming first that they were in for-profit plans (Model 1) and then that they were in nonprofit plans (Model 2). The magnitude of the estimates of the effects of for-profit status on access was very similar across the two models and was also very similar to those reported in the body of the article for the Medicaid enrollees who were able to provide a valid plan name; however, as would be expected given the measurement error introduced in the measure of whether the individual is enrolled in a for-profit plan under Models 1 and 2, the standard errors in those two models were quite large.

4. InterStudy, "Competitive Edge 10.2, Part 1: HMO Directory," St. Paul, MN, 2000 and "Competitive Edge 11.2, Part 1: HMO Directory," St. Paul, MN, 2001.

5. Although there is no Medicaid eligibility category for childless adults (i.e., adults without minor children present in their family), a few states have expanded Medicaid coverage to some low-income childless adults through Section 1115 Medicaid waivers. Those individuals are not included in the analysis. 
6. In the context of the model being estimated here, these are the LM and Wald versions of the Kleibergen-Paap ranktest statistic and the Kleibergen-Paap Wald ranktest $F$ statistic, as calculated by the ivreg2 command in Stata.

\section{References}

Andersen, R. (1995). Revisiting the behavioral model of access to medical care: Does it matter? Journal of Human and Social Behavior, 36, 1-10.

Andersen, R. M., \& Newman, J. F. (1973). Societal and individual determinants of medical care utilization in the United States. Milbank Quarterly, 51(1), 95-124.

Bloom, J. R., Hu, T. W., Wallace, N., Cuffel, B., Hausman, J. W., Sheu, M. L., et al. (2002). Mental health costs and access under alternative capitation systems in Colorado. Health Services Research, 37, 315-340.

Brick, J. M., Ferraro, D., \& Strickler, T. (2004). Variance estimation for the 2002 NSAF. 2002 NSAF Methodology Report No. 4. Retrieved March 20, 2008, from http://www.urban.org/center/anf/ 2002methodology.cfm

Centers for Medicare and Medicaid Services. (2005). National summary of Medicaid managed care programs and enrollment as of June 30, 2005. Retrieved March 20, 2008, from www.cms .hhs.gov/MedicaidDataSourcesGenInfo/Downloads/mmcer05.pdf

Flores, G., Abreu, M., Sun, D., \& Tomany, S. C. (2004). Urban parents' knowledge and practices regarding managed care. Medical Care, 42, 336-345.

Hill, S.C., Thornton, C., Trenholm, C., \& Wooldridge, J. (2002). Risk selection among SSI enrollees in TennCare. Inquiry, 39, 152-167.

McClellan, M. B., \& Newhouse, J. P. (2000). Overview of the special supplement issue. Health Services Research, 35, 1061-1069.

Reschovsky, J. D., \& Hargraves, J. L. (2000). Health care perceptions and experiences: It's not whether you are in an HMO, it's whether you think you are [Issue Brief, No. 30]. Washington, DC: Center for Health System Change.

Schlesinger, M., Mitchell, S., \& Gray, B. (2003). Measuring community benefits provided by nonprofit and for-profit HMOs. Inquiry, 40(Summer), 114-132.

Schlesinger, M., Quon, N., Wynia, M., Cummins, D., \& Gray, B. (2005). Profit-seeking, corporate control, and the trustworthiness of health care organizations: Assessments of health plan performance by their affiliated physicians. Health Services Research, 40, 274-486.

Shenkman, E., Wu, S. S., Nackashi, J., \& Sherman, J. (2003). Managed care organizational characteristics and health care use among children with special health care needs. Health Services Research, 38, 1599-1624.

StataCorp. (2007). Stata statistical software: Release 10. College Station, TX: StataCorp LP.

Wooldridge, J. (2002). Econometric analysis of cross section and panel data. Cambridge, MA: MIT Press. 